\section{Enhancing immunity}

Immunopotentiation (Ciba foundation Symposium 18, New Series.) Pp. ix+ 335. (Elsevier/Excerpta Medica/NorthHolland, Associated Scientific Publishers: Amsterdam, London and New York, 1973). Df. $47.50 ; \$ 18.30$.

This symposium deals with the effects of substances (adjuvants) which can stimulate the immune response to unrelated antigens. This topic is of obvious interest as far as control of the immune response is concerned, but becomes of major importance because of its clinical significance. Adjuvants can help in cancer therapy, and the proceedings summarise the situation in this area, and suggest mechanisms whereby adjuvants may be acting.

Convincing evidence is presented of the efficacy of immunotherapy for cancer treatment in laboratory animals and human disease. A rationale for the use of adjuvants in some human leukaemias is clearly advanced by Mathé. If chemotherapy is first used to reduce the tumour mass, immunotherapy involving the injection of BCG and killed tumour cells can be strikingly successful in prolonging remission of the discase.

It seems unlikely that the agents useful in cancer therapy act on the immune system, mainly because they are also powerful adjuvants for many well characterised immune responses. The effects of adjuvants on these responses is also dealt with. Some participants suggest that adjuvants may potentiate the trapping of lymphocytes in lymph nodes or spleen and improve cell interactions. Others favour the view that adjuvants directly stimulate cells involved in immune responses. In this regard the $\mathrm{B}$ lymphocyte, $\mathrm{T}$ lymphocyte, macrophage triangle is dominant, and effects on all three cell types are proposed. Perhaps one can generalise to say that macrophages certainly seem to be strongly involved in adjuvant action, and that different adjuvants can have effects biased towards B or T lymphocyte responses. Some can even potentiate one type of immune response and suppress another.

As the proceedings make clear, what is needed is an understanding of the control mechanisms involved, and hopefully the discovery of methods of selectively stimulating or suppressing the different types of immune response.

Ciba Symposium 18 should be of great interest to those studying the immune response or cancer therapy. Immunopotentiation is a confusing subject, and the presentation of the 1973 state of play is of great value; the discussions of the participants are particularly useful. It is clear that there is work to be done, and anyone reading the volume should find a few ideas to begin with.

\section{A. F. Williams}

\section{Creative stimulus}

Population Growth: Anthropological Implications. Edited by Brian Spooner. Pp. xxvii + 425. (MIT: Cambridge Massachusetts and London, 1973.) \$15; $£ 6.75$.

Tris collection of papers considers various anthropological problems in the light of the population theories of Ester Boserup ${ }^{1}$. She considers that human population growth acts as an independent variable in the development of culture and society. Population growth is not inexorably limited by the level of resources through the agency of 'misery and vice' but instead stimulates invention to generate new resources or new techniques for exploiting old resources.

There are seventeen papers in all. The first six are concerned with archaeological evidence. A mass of archaeological data is presented for Mesoamerica, Mesopotamia and Egypt. Sometimes this is accompanied by population density estimates, sometimes not. In most of these papers the relationship of population change, resource exploitation and economic theory is treated very much as a postscript.

Bronson's paper "Farm Labour and the Evolution of Food Production" is one of the few where theory is discussed 2t length. According to Boserup, farmers will always prefer easy extensive cultivation (like shifting cultivation) until they are forced to intensify methods by population pressure. Furthermore, farmers will revert to shifting cultivation if population size falls. But where population is known to have fallen, as in Europe after Rome's fall, no such agricultural change is seen. Bronson also complains that the more elaborate stages of agriculture should not necessarily be regarded as being more 'adaptive' than the simpler ones, especially when the latter are still represented in present-day economies. If Boserup were correct, shifting agriculture would be extinct, whereas it is still widely practiced in areas which could support more intensive systems.

Most of the rest of the book deals with present-day populations from the viewpoint of social anthropology. One paper considers the importance of religious organisation and suzerainty in achieving political centralisation. Another describes conditions in Tibet which support Boserup's theory through its obverse: despite a superabundance of resources a population declines for non-economic reasons and migration takes place into the area of its most extensive deployment; high altitude nomadic pastoralism. One of the most interesting papers presents calculations to show how the problems of carrying children force the nomadic Kung bushmen to prolong the interval between births; a type of problem not dealt with in Boserup's economic formulations.

As a discussion of Boserup's theory in relation to anthropology this book is a disappointment, and the title is certainly misleading. The archaeological data are doubtless interesting in themselves and some of the population estimates may be useful. But demographic data from archaeological and ancient literary sources are unreliable and may always remain so. Associations may be established between past population growth and technical change, but Boserup's theory seems to require population change to occur first and, of course, for the postulated mechanism to be responsible. This would be difficult enough to establish in a modern population and it is not clear how the necessarily less detailed information from archaeology could hope to validate such a theory.

But most of the papers on modern populations are also unable to demonstrate the importance of the demographic factor, partly through their lamentable lack of numerical information. In many cases no demographic data are quoted, population is rarely mentioned and resources are not evaluated.

It is very surprising that no reference is made to historical European populations whose demography and economics are much better known than those of ancient Egypt or Mesopotamia. Exogenous technical innovations, which have had profound demographic consequences, might also have been germane to these discussions. But the introduction of the potato to Europe, or of European sanitary and medical knowledge to the Third World, are nowhere mentioned.

It seems that many archaeologists and anthropologists need to know more demography. The difficulty of establishing a trustworthy case for population change does not seem to be appreciated, the impossibility of sustained population growth or decline for more than a short time is not realised, and the views of Malthus and other theorists (often thought to be in opposition to Boserup) are widely misunderstood by the contributors to this book.

\section{A. Coleman}

${ }^{1}$ Boserup, E., The Conditions of Agricultural Growth: The ecomomics of Agricultural change under Population Pressure (Aidine, Chicago, 1965) 